\title{
Pemodelan ARIMA Dalam Prediksi Penumpang Pesawat Terbang Pada Bandara Internasional Sam Ratulangi Manado
}

\author{
Sinnyo H.A. Salmon ${ }^{1}$, Nelson Nainggolan ${ }^{2}$ Djoni Hatidja $^{3}$ \\ ${ }^{1}$ Program Studi Matematika, FMIPA, UNSRAT, sinnyosalmon@ymail.com \\ ${ }^{2}$ Program Studi Matematika, FMIPA, UNSRAT, bapaivana@yahoo.co.id \\ ${ }^{3}$ Program Studi Matematika, FMIPA, UNSRAT, dhatidja@yahoo.com
}

\begin{abstract}
Abstrak
Analisis time series model ARIMA dapat digunakan untuk melakukan perkiraan maupun prediksi pada masa yang akan datang. Data pengamatan banyaknya penumpang pesawat dapat dipandang sebagai data time series. Tujuan penelitian ini ialah menentukan model time series yakni model ARIMA dari banyaknya penumpang pesawat domestik di Bandara Internasional Sam Ratulangi Manado. Kemudian memprediksi (prediction) jumlah penumpang pesawat domestik di Bandara Internasional Sam Ratulangi Manado untuk 6 bulan. Data yang digunakan pada penelitian ini adalah data sekunder yang diperoleh dari PT. Angkasa Pura I di Bandara Internasional Sam Ratulangi yang berupa data jumlah penumpang pesawat di Bandara Internasional Sam Ratulangi bulan Januari 2003 sampai Juni 2014. Data yang diambil adalah banyaknya penumpang pesawat baik yang datang ke Bandara Internasional Sam Ratulangi maupun yang berangkat dari Bandara Internasional Sam Ratulangi. Hasilnya model time series untuk jumlah penumpang pesawat domestik pada Bandara Internasional Sam Ratulangi Manado adalah ARIMA musiman $(1,1,1)(1,1,1)^{12}$ dengan hasil prediksi bulan Januari 2015 sebanyak 171794 penumpang, bulan Februari 2015 sebanyak 173398 penumpang, bulan Maret 2015 sebanyak 165233 penumpang, bulan April 2015 sebanyak 170892 penumpang, bulan Mei 2015 sebanyak 158937 penumpang dan bulan Juni 2015 sebanyak 164245 penumpang.
\end{abstract}

Kata Kunci : Bandara Internasional Sam Ratulangi , Metode ARIMA

\section{ARIMA Modeling In Prediction Passenger Aircraft At The International Airport Sam Ratulangi In Manado}

\begin{abstract}
Analysis of time series ARIMA model can be used to make forecasts and predictions on the future. The number of air passengers observational data can be seen as time series data. The purpose of this study is to determine the time series model ARIMA models of many domestic air passengers in Sam Ratulangi International Airport. Then Predicting (prediction) the number of domestic air passengers in Sam Ratulangi International Airport for 6 months. The data used in this research is secondary data obtained from PT. AngkasaPura I Sam Ratulangi International Airport in the form of data on the number of passengers at Sam Ratulangi International Airport in January 2003 to June 2014. The data is taken from the number of passengers who came to Sam Ratulangi International Airport as well as those departing from Sam Ratulangi International Airport. The result time series models for the number of domestic air passengers at Sam Ratulangi International Airport is a seasonal ARIMA $(1,1,1)(1,1,1)^{12}$ with the results predicted in January 2015 is 171794 passengers, in February 2015 is 173398 passengers, in March 2015 is 165233 passengers, in April 2015 is 170892 passengers, in May 2015 is158937 passengers, and in June 2015 is 164245 passengers.
\end{abstract}

Keywords: Sam Ratulangi International Airport, ARIMA Method

\section{Pendahuluan}

Peraturan Menteri Nomor 69 Tahun 2013 tentang Tataan Kebandarudaraan Nasional definisi bandar udara adalah kawasan di daratan dan/atau perairan dengan batas-batas tertentu yang digunakan sebagai tempat pesawat udara mendarat dan lepas landas, naik turun penumpang, bongkar muat barang, dan tempat perpindahan intra dan antarmoda transportasi, yang dilengkapi 
dengan fasilitas keselamatan dan keamanan penerbangan, serta fasilitas pokok dan fasilitas penunjang lainnya [1].

PT. Angkasa Pura I berada di Bandara Internasional Sam Ratulangi yang terletak di kecamatan Mapanget, Manado. Saat ini terdapat 21 maskapai penerbangan yang ada di Indonesia, 7 maskapai penerbangan diantaranya beroperasi di Sulawesi Utara untuk jalur penerbagan domestik dan 1 maskapai untuk jalur penerbagan internasional. Analisis time series (runtun waktu) banyak digunakan dalam berbagai bidang, misalnya ekonomi, teknik, geofisik, pertanian dan kedokteran. Runtun waktu adalah suatu deret observasi yang berurut dalam waktu.

Analisis time series model ARIMA dapat digunakan untuk melakukan estimasi maupun peramalan pada masa yang akan datang. Data pengamatan banyaknya penumpang pesawat dapat dipandang sebagai data time series. Tujuan penelitian ini ialah menentukan model time series yakni model ARIMA dari banyaknya penumpang pesawat domestik di Bandara Internasional Sam Ratulangi Manado. Kemudian memprediksi (prediction) jumlah penumpang pesawat domestik di Bandara Internasional Sam Ratulangi Manado untuk 6 bulan.

\section{Model Autoregresif (Autoregressive)}

Model autoregresif disingkat AR adalah model yang menyatakan bahwa data pada periode sekarang dipengaruhi oleh data pada periode sebelumya. Model Autoregresif dengan ordo $p$ disingkat dengan ARIMA $(p, 0,0)$. Bentuk umum dari model ini adalah sebagai berikut [2].

$$
Z_{t}=\mu+\phi_{1} Z_{t-1}+\phi_{2} Z_{t-2}+\ldots+\phi_{p} Z_{t-p}+e_{t}
$$

dimana :

$$
\begin{array}{ll}
\mu & : \text { Konstanta } \\
\phi_{1}, \phi_{2}, \phi_{p} & : \text { Koefisien parameter autoregresif ke- } p \\
Z_{t-1}, Z_{t-2}, Z_{t-p} & : \text { Variabel bebas } \\
e_{t} & : \text { Sisaan pada saat ke- } t
\end{array}
$$

\section{Model Rata-rata Bergerak (Moving Average)}

Model Rata-rata Bergerak (Moving Average) disingkat MA menyatakan hubungan antara nilai pengamatan dari kesalahan peramalan sekarang dan masa lalu yang berurutan, persamaan itu dianamakan moving average model. Model moving average dengan orde $q$ disingkat $\operatorname{MA}(q)$ atau ARIMA $(0,0, q)$. Bentuk umum dari model ini sebagai berikut [3] :

$$
Z_{t}=\mu+e_{t}-\theta_{1} e_{t-1}-\theta_{2} e_{t-2}-\ldots-\theta_{p} e_{t-q}
$$

dimana :

$$
\begin{array}{ll}
\mu & : \text { Konstanta } \\
\theta_{1}, \theta_{2}, \theta_{p} & : \text { Koefisien parameter moving average ke- } q \\
e_{t} & : \text { Sisaan pada saat ke- } t
\end{array}
$$

\section{Model ARMA (Autoregressive Moving Average)}

Model ARMA (Autoregressive Moving Average) ialah gabungan dari model $\operatorname{AR}(p)$ dan $\operatorname{MA}(q)$ sehingga memiliki asumsi bahwa data periode sekarang dipengaruhi oleh data perode lampaunya dan nilai lampau kesalahannya. Model ARMA dengan orde $p$ dan $q$ ditulis $\operatorname{ARMA}(p, q)$ atau ARIMA $(p, 0, q)$. Bentuk umum dari model ini adalah sebagai berikut [3]: 


$$
Z_{t}=\mu+\phi_{1} Z_{t-1}+\phi_{2} Z_{t-2}+\ldots+\phi_{p} Z_{t-p}+e_{t}-\theta_{1} e_{t-1}-\theta_{2} e_{t-2}-\ldots-\theta_{q} e_{t-q}
$$

dimana :

$$
\begin{array}{ll}
Z_{t} & : \text { Variabel tak bebas } \\
\mu & : \text { Konstanta } \\
\theta_{1}, \theta_{2}, \theta_{q} & : \text { Koefisien parameter moving average ke- } q \\
\phi_{1}, \phi_{2}, \phi_{p} & : \text { Koefisien parameter autoregressive ke- } p \\
Z_{t-1}, Z_{t-2}, Z_{t-p} & : \text { Variabel bebas } \\
e_{t-q} & : \text { Sisaan pada saat ke-t- } q
\end{array}
$$

\section{Proses Selisih (Differencing)}

Metode pembedaan (differencing) dilakukan dengan cara mengurangi nilai data pada suatu periode dengan nilai data periode sebelumnya yang dapat dirumuskan sebagai berikut :

$$
W_{t}=Z_{t}-Z_{t-1}
$$

\section{Model ARIMA (Autoregrssive Integrated Moving Average)}

Model time series yang digunakan berdasarkan asumsi bahwa data time series tersebut stasioner artinya rata-rata dan varian suatu data time series konstan. Jika data time series tidak stasioner maka metode yang digunakan untuk membuat data stasioner yaitu dilakukan dengan diffencing untuk data yang tidak stasioner dalam rata-rata dan proses transformasi untuk data yang tidak stasioner dalam varian [2].

Proses ARIMA adalah model time series yang tidak stasioner. Secara umum persamaan model ARIMA adalah :

$$
\begin{aligned}
Z_{t}-Z_{t-1}= & \phi_{1}\left(Z_{t-1}-Z_{t-2}\right)+\phi_{2}\left(Z_{t-2}-Z_{t-3}\right)+\ldots+\phi_{p 1}\left(Z_{t-p}-Z_{t-p-1}\right) \\
& +e_{t}-\theta_{1} e_{t-1}-\ldots-\theta_{q} e_{t-q}
\end{aligned}
$$

\section{Faktor Musiman (seasonality) Dalam Suatu Deret Berkala}

Suatu pola yang berulang-ulang dalam selang waktu yang tetap didefinisikan sebagai pola musiman. Untuk data yang stasioner, faktor musiman dapat ditentukan dengan mengidentifikasi koefisien autokorelasi pada dua atau tiga time lag yang berbeda nyata dari nol. Sebagai contoh untuk data yang dikumpulkan bulanan, pembedaan satu musiman penuh (tahun) dapat dihitung sebagai berikut:

$$
X_{t}^{\prime}=X_{t}-X_{t-12}=\left(1-B^{12}\right) X_{t}
$$

Notasi ARIMA dapat diperluas untuk menangani aspek musiman, notasi umum yang disingkat adalah [4]:

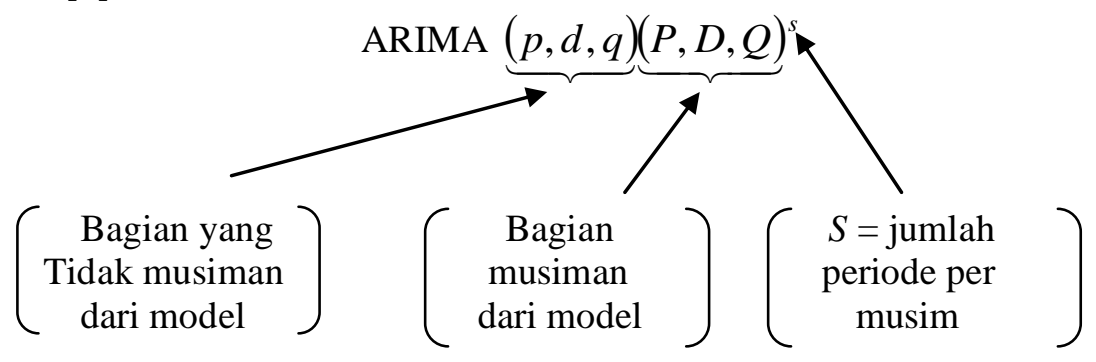




\section{Metodologi Penelitian}

Data yang digunakan pada penelitian ini adalah data sekunder yang diperoleh dari PT. Angkasa Pura I di Bandara Internasional Sam Ratulangi yang berupa data jumlah penumpang pesawat di Bandara Internasional Sam Ratulangi bulan Januari 2003 sampai Juni 2014. Data yang diambil adalah banyaknya penumpang pesawat baik yang datang ke Bandara Internasional Sam Ratulangi maupun yang berangkat dari Bandara Internasional Sam Ratulangi. Langkah-langkah penerapan model ARIMA sebagai berikut :

1) Pengumpulan Data

2) Plot Data

3) Pemeriksaan Kestasioneran Data

4) Identifikasi Model ARIMA

5) Penentuan Parameter

6) Penentuan Persamaan Model ARIMA

7) Validasi Model

8) Prediksi

\section{Hasil dan Pembahasan}

\subsection{Jumlah Penumpang Pesawat Bandara Sam Ratulangi Periode Bulan Januari 2003 sampai dengan Bulan Juni 2014}

Data jumlah penumpang pesawat Bandara Sam Ratulangi periode bulan Januari 2003 sampai dengan bulan Juni 2014 sebanyak 138 data dapat dilihat pada Time series plot Gambar 1.

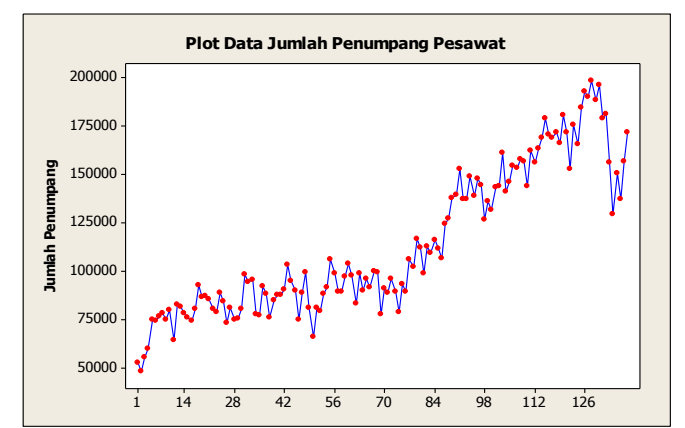

Gambar 1. Plot Data Jumlah Penumpang Pesawat Domestik Periode Bulan Januari 2003 sampai dengan Bulan Juni 2014

Berdasarkan plot pada Gambar 1 menunjukkan jumlah penumpang pesawat periode bulan Januari 2003 dimulai dari 52602 penumpang kemudian mengalami penurunan pada bulan Februari kemudian naik kembali pada bulan Maret menjadi 55559 penumpang, terus naik sampai pada akhir tahun 2003 yaitu pada bulan Desember sebanyak 82755 penumpang. Pada bulan Agustus 2013 merupakan jumlah penumpang terbanyak yakni 197994 penumpang kemudian mengalami penurunan secara drastis pada bulan Februari 2014 dengan total penumpang sebanyak 129295 penumpang kemudian naik kembali sampai pada bulan Juni 2014 dengan total penumpang sebanyak 171517.

Dari Gambar 1 terlihat bahwa data menunjukkan pola trend atau berubah-ubah. Oleh karena itu, dapat dikatakan data belum stasioner. Untuk melihat kestasioneran data dapat dilihat melalui pengidentifikasi nilai koefisien Fungsi Autokorelasi (ACF) dan Fungsi Autokorelasi Parsial (PACF) pada Gambar 2 dan 3.

Dari Gambar 2 terlihat bahwa perilaku Fungsi Autokorelasi (ACF) dari lag 1 dan lag 2 secara perlahan mengecil mendekati nol sedangkan pada Gambar 3 terlihat perilaku Fungsi Autokorelasi Parsial (PACF) mendekati nol setelah lag pertama. Kedua hal ini mengidentifikasikan bahwa data tersebut tidak bersifat stasioner sedangkan dalam analisis ARIMA dibutuhkan data yang bersifat stasioner. Maka dari itu perlu dilakukan proses selisih (differencing). 


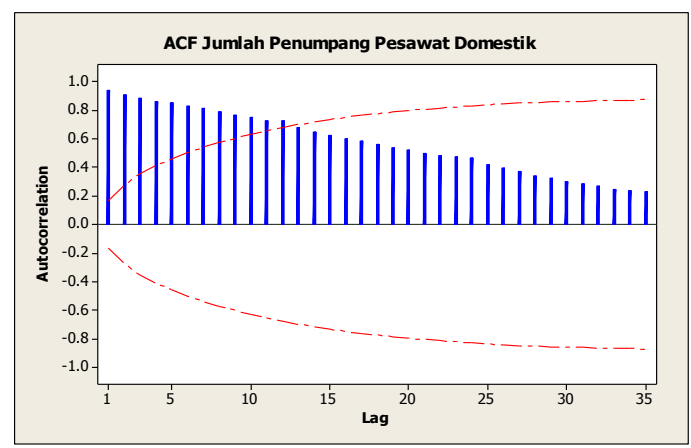

Gambar 2. Fungsi Autokorelasi Data Jumlah Penumpang Pesawat Domestik Periode Bulan Januari 2003 sampai dengan Bulan Juni 2014

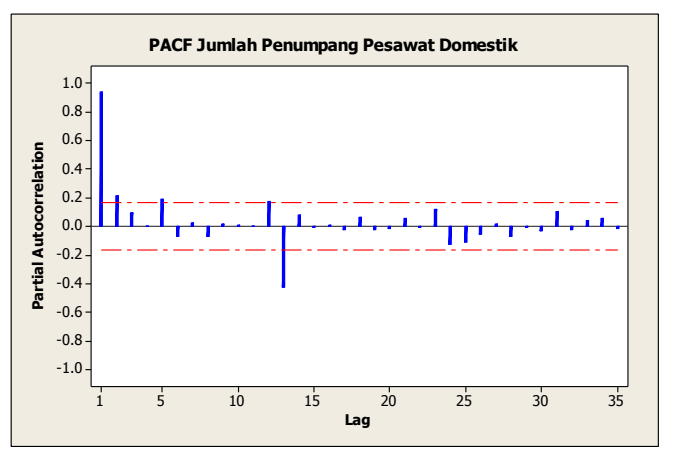

Gambar 3. Fungsi Autokorelasi Parsial Data Jumlah Penumpang Domestik Pesawat Periode Bulan Januari 2003 sampai dengan Bulan Juni 2014

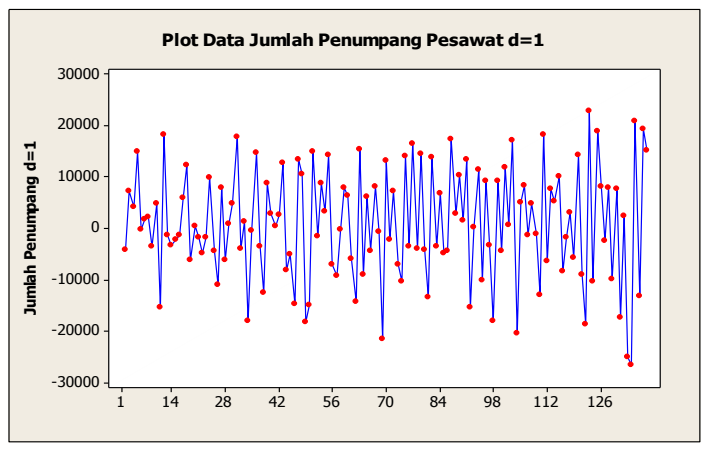

Gambar 4. Plot Data Jumlah Penumpang Pesawat Domestik Periode Bulan Januari 2003 sampai dengan Bulan Juni 2014 Dengan Selisih Orde 1

Pada Gambar 4 menunjukkan bahwa data telah stasioner dan mengindikasi adanya musiman setelah dilakukan proses selisih satu kali . Pengidentifikasian data telah stasioner dapat dilihat juga dalam grafik Fungsi Autokorelasi (ACF) dan Fungsi Autokorelasi Parsial (PACF) seperti pada Gambar 5 dan 6.

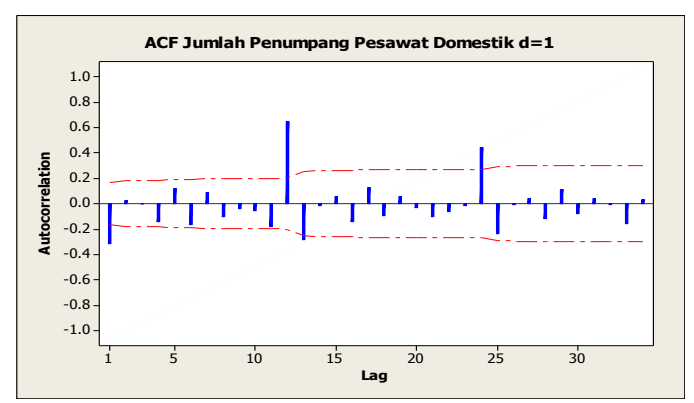

Gambar 5. Fungsi Autokorelasi Data Jumlah Penumpang Pesawat Domestik Periode Bulan Januari 2003 sampai dengan Bulan Juni 2014 Dengan Selisih Orde 1 


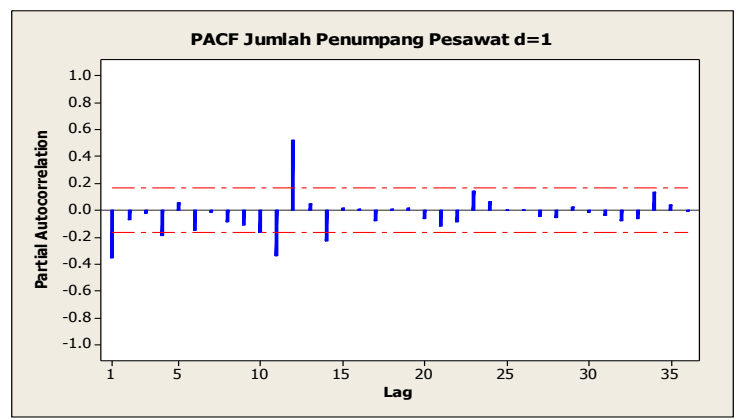

Gambar 6. Fungsi Autokorelasi Parsial Data Jumlah Penumpang Pesawat Domestik Periode Bulan Januari 2003 - Juni 2014 Dengan Selisih Orde 1

Pada Gambar 5 terlihat bahwa koefisien ACF menurun secara eksponensial menuju nol hal serupa juga ditunjukkan oleh koefisien dari PACF setelah lag pertama mengindikasikan bahwa data telah bersifat stasioner. Dengan menggunakan software Statistika hasil identifikasi dari Gambar 5 dan Gambar 6 menghasilkan kemungkinan model prediksi seperti pada Tabel 1.

Tabel 1. Kemungkinan Model Prediksi Jumlah Penumpang Pesawat Domestik Bandara Internasional Sam Ratulangi Manado

\begin{tabular}{|c|c|}
\hline Model & $\begin{array}{c}\text { MeanSquared Error } \\
\text { (MSE) }\end{array}$ \\
\hline$(0,1,1)(1,1,1)^{12}$ & 47081165 \\
\hline$(1,1,1)(1,1,1)^{12}$ & 47212427 \\
\hline$(2,1,1)(1,1,1)^{12}$ & 47644246 \\
\hline$(1,1,0)(1,1,1)^{12}$ & 46835221 \\
\hline$(1,1,2)(1,1,1)^{12}$ & 47719802 \\
\hline
\end{tabular}

Dari Tabel 1 terdapat 5 model dengan proses differencing 1 kali yang akan digunakan untuk mempridiksi Jumlah Penumpang Pesawat Domestik pada Bandara Internasional Sam Ratulangi Manado. Model yang terbaik adalah model dengan nilai dari MSE yang paling kecil. Namun model yang akan digunakan adalah model dalam penelitian ini adalah model ARIMA $(1,1,1)(1,1,1)^{12}$ dengan nilai MSE 47212427. Hal ini dikarnakan model tersebut setelah validasi menggasilkan nilai MSE terkecil dari ke lima model. Model ARIMA $(1,1,1)(1,1,1)^{12}$ dengan parameter $p=1, d=1, q=1, P=1, D=1$, dan $Q=1$ atau ARIMA $(1,1,1)(1,1,1)^{12}$ adalah model yang akan digunakan dalam memprediksi Jumlah Penumpang Pesawat Domestik pada Bandara Internasional Sam Ratulangi Manado.

\subsection{Menentukan Persamaan ARIMA $(p, d, q)(P, D, Q)^{12}$ Pada Data Jumlah Penumpang Pesawat Domestik Bandara Internasional Sam Ratulangi Manado}

Berdasarkan hasil penetuan parameter diperoleh model ARIMA $(1,1,1)(1,1,1)^{12}$ dengan koefisien AR $1:-0.3149$, SAR $12: 0.4361$, MA $1:-0.0690$, SMA $12: 0.8457$ dan konstanta : -122.5 .

Dibuat persamaan untuk model ARIMA $(1,1,1)(1,1,1)^{12}$ menjadi :

$$
\begin{aligned}
&\left(1-\phi_{1} B\right)\left(1-\Phi_{1} B^{12}\right)(1-B)\left(1-B^{12}\right) X_{t}=\left(1-\theta_{1} B\right)\left(1-\Theta_{1} B^{12}\right) e_{t} \\
& X_{t}=\left(1+\phi_{1}\right) X_{t-1}+\left(1+\Phi_{1}\right) X_{t-12}-\left(1+\phi_{1}+\Phi_{1}+\phi_{1} \Phi_{1}\right) X_{t-13}+\left(\phi_{1}+\phi_{1} \Phi_{1}\right) X_{t-14}-\Phi_{1} X_{t-24} \\
&+\left(\Phi_{1}+\phi_{1} \Phi_{1}\right) X_{t-25}-\left(\phi_{1} \Phi_{1}\right) X_{t-26}+e_{t}-\theta_{1} e_{t-1}-\Theta_{1} e_{t-12}+\theta_{1} \Theta_{1} e_{t-13}+\mu \\
& X_{t}= 0.68 X_{t-1}+1.43 X_{t-12}-0.6252 X_{t-13}+(-0.4522) X_{t-14}-0.4361 X_{t-24}+0.2988 X_{t-25} \\
&-(-0.1373) X_{t-26}+(-0.0690) e_{t-1}-0.8457 e_{t-12}+0.0583 e_{t-13}+(-122.5)
\end{aligned}
$$


Setelah persamaan didapatkan selanjutnya dilakukan proses diagnostik untuk melihat tingkat kesalahan model yaitu dengan melihat Histogram of Residual, ACF of Residual dan Normal Probability Plot of Residual yang akan ditunjukkan oleh Gambar 7, 8, dan 9.

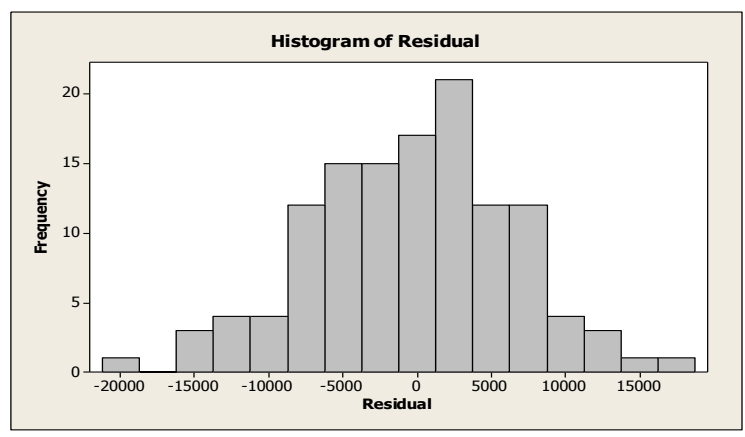

Gambar 7. Histogram of Residual Jumlah Penumpang Pesawat Domestik Bandara Internasional Sam Ratulangi Manado

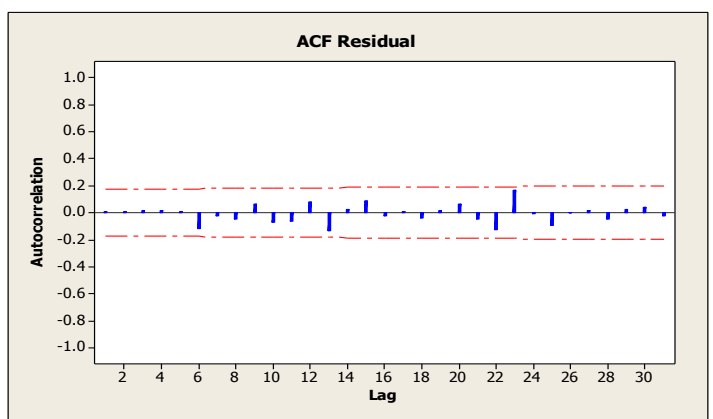

Gambar 8. ACF of Residual Jumlah Penumpang Pesawat Domestik Bandara Internasional Sam Ratulangi Manado

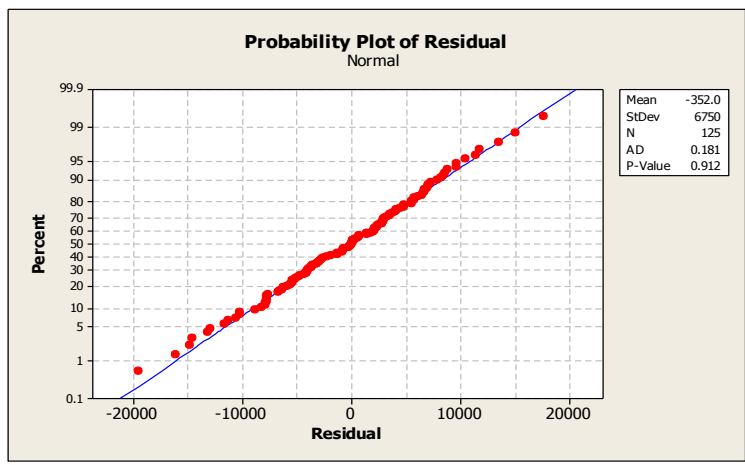

Gambar 9. Normal Probability Plot of Residual Jumlah Penumpang Pesawat Domestik Bandara Internasional Sam Ratulangi Manado

Pada Gambar 7 terlihat grafik Histogram of Residual membentuk diagram normal hal ini menandakan bahwa residual berdistribusi normal. Selanjutnya untuk asumsi White Noise dimana residual harus bersifat random dan berdistribusi normal. Pada Gambar 8 dimana terlihat bahwa semua bar tidak melebihi garis putus-putus, itu berarti residual bersifat random atau acak. Pada Gambar 9 terlihat bahwa residual mengikuti garis garis diagonal yang mengartikan bahwa residual berdistribusi normal. Residual yang bersifat random atau acak dan berdistribusi normal menandakan bahwa Asumsi White Noise sudah terpenuhi.

\subsection{Validasi Prediksi Jumlah Penumpang Pesawat Domestik Bandara Internasional Sam Ratulangi Manado}

Validasi digunakan untuk mengetahui kondisi data yang sebenarnya (aktual) dengan hasil prediksi sehingga dapat membandingkan kedua kondisi data tersebut. 


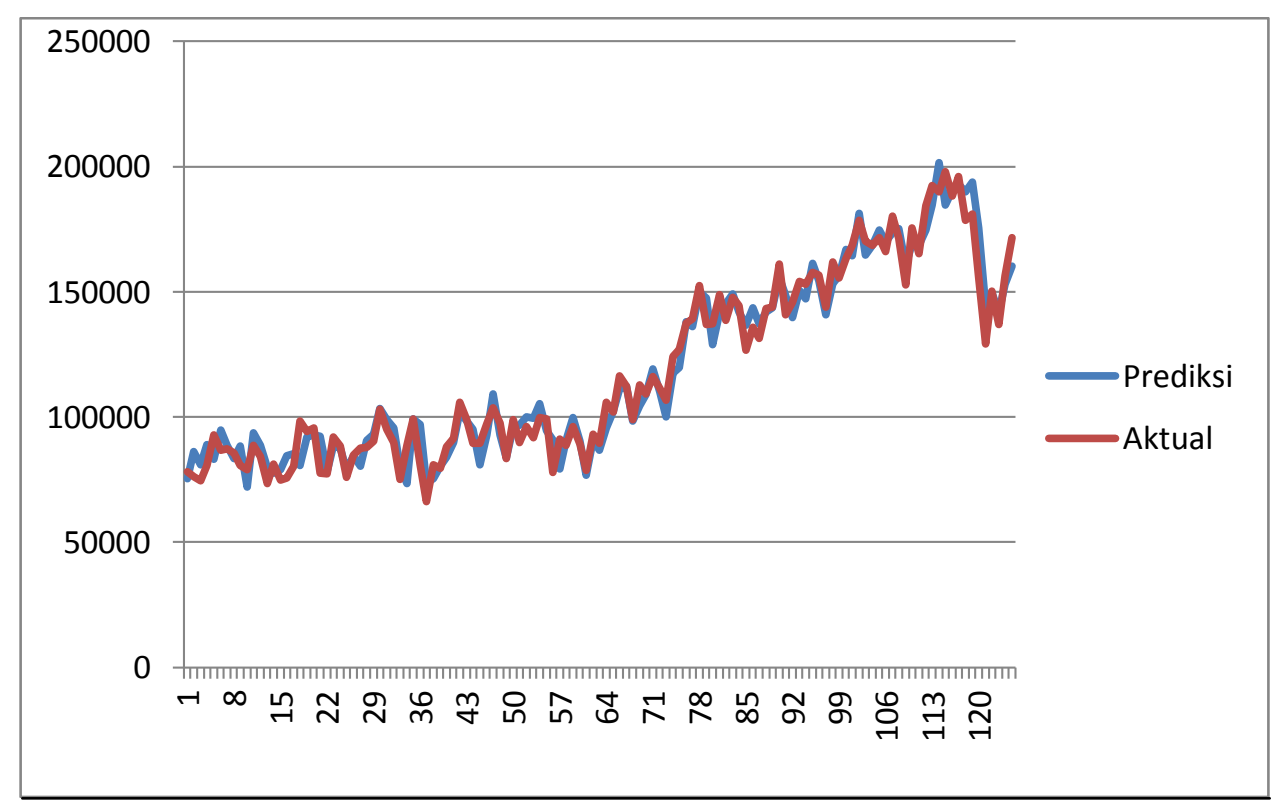

Gambar 10. Data Jumlah Penumpang Pesawat Domestik Sebenarnya dan Prediksinya Bulan Februari 2004 sampai Juni 2014.

Gambar 10 terlihat bahwa jumlah penumpang pesawat domestik periode bulan Februari 2004 sampai bulan Desember 2014 tidak terlalu berbeda jauh dengan hasil Prediksi. Terlihat keakuratan model prediksi setiap bulannya saling tumpang tindih. Karena itu model ARIMA $(1,1,1)(1,1,1)^{12}$ bisa digunakan untuk memprediksi jumlah penumpang pesawat domestik pada periode bulan Januari 2015 sampai Juni 2015.

\subsection{Prediksi Jumlah Penumpang Pesawat Domestik Bandara Internasional Sam Ratulangi Manado Periode 6 bulan}

Langkah terakhir dalam analisis time series adalah prediksi (prediction). Dalam penelitian ini akan diprediksi untuk periode 6 bulan. Hasil prediksi dengan mengunakan model ARIMA $(1,1,1)(1,1,1)^{12}$ untuk Jumlah Penumpang Pesawat Domestik Bandara Internasional Sam Ratulangi Manado dituangkan dalam Tabel 2.

Tabel 2. Hasil Prediksi Jumlah Penumpang Pesawat Domestik Bandara Internasional Sam Ratulangi Manado Periode Bulan Juli 2014 sampai Bulan Juni 2015.

\begin{tabular}{|c|c|c|}
\hline Periode & Prediksi & Aktual \\
\hline Juli 2014 & 171794 & 160766 \\
\hline Agustus 2014 & 173398 & 183038 \\
\hline September 2014 & 165233 & 163600 \\
\hline Oktober 2014 & 170829 & 172673 \\
\hline November 2014 & 158937 & 166340 \\
\hline Desember 2014 & 164245 & 180767 \\
\hline Januari 2015 & 171794 & - \\
\hline Februari 2015 & 173398 & - \\
\hline Maret 2015 & 165233 & - \\
\hline April 2015 & 170829 & - \\
\hline Mei 2015 & 158937 & - \\
\hline Juni 2015 & 164245 & - \\
\hline
\end{tabular}


Hasil prediksi untuk jumlah penumpang pesawat domestik bandara internasional Sam Ratulangi Manado dimulai dari bulan Juli 2014 sampai Juni 2015. Pada bulan Januari 2015 terjadi penurunan Jumlah penumpang dan pada bulan Mei 2015 merupakan prediksi jumlah penumpang pesawat domestik terendah, yakni sebanyak 158937 penumpang kemudian naik kembali pada bulan Juni 2015 hingga 164245 penumpang.

\section{Kesimpulan}

- Model time series untuk prediksi jumlah penumpang pesawat domestik pada Bandara Internasional Sam Ratulangi Manado, menggunakan data periode Januari 2003 sampai Desember 2014 adalah ARIMA musiman $(1,1,1)(1,1,1)^{12}$

- Model prediksi jumlah penumpang pesawat domestik pada Bandara Internasional Sam Ratulangi Manado cukup baik untuk rentang periode 6 bulan yakni bulan Januari 2015 sebanyak 171794 penumpang, bulan Februari 2015 sebanyak 173398 penumpang, bulan Maret 2015 sebanyak 165233 penumpang, bulan April 2015 sebanyak 170892 penumpang, bulan Mei 2015 sebanyak 158937 penumpang dan bulan Juni 2015 sebanyak 164245 penumpang.

\section{Daftar Pustaka}

[1] Peraturan Menteri Perhubungan, 2013. Peraturan Menteri No. 69 Tahun 2013 tentang Tatanan Kebandarudaraan Nasional. Jakarta

[2] Mulyana, 2004. Buku Ajar Analisis Deret Waktu. Universitas Padjajaran FMIPA Jurusan Statistika, Bandung.

[3] Mulyono, S. 2000. "Peramalan Harga Saham dan Nilai Tukar : Teknik Box-Jenkins". Ekonomi dan Keuangan Indonesia 48(2).

[4] Makridakis, S., S.C. Wheelwright \& V.E. McGee. 1999. Metode dan Aplikasi Peramalan Jilid 1 Edisi Kedua. Terjemahan S. Andriyanto dan A.Basith. Erlangga, Jakarta. 